\title{
Paper strength improvement by inclusion of nano-ligno- cellulose to Chemi-thermomechanical pulp
}

\section{Sinke H. Osong, Sven Norgren and Per Engstrand}

KEYWORDS: CTMP, Fractionation, Nano-lignocellulose, Handsheet, Mechanical strength properties

SUMMARY: So far, chemical pulp fibres have been utilized as conventional stock materials for nanocellulose production. The main aim of this work is to use stock materials from mechanical or chemi-thermomechanical pulping process to produce lignin containing nanofibres, which are referred to as nano-ligno-cellulose (NLC) in this study. The present study shows the influence on handsheets of chemi-thermomechanical pulp (CTMP) fibres blended with NLC. For comparison reasons, nanocellulose (NC) from bleached kraft pulp (BKP) was produced in a similar approach as NLC. Both the NLC and the $\mathrm{NC}$ were blended with their respective pulp fibres and their corresponding handsheets properties were evaluated with respect to sheet density. It was found that the handsheets of pulp fibres blended with NLC/NC improved the mechanical properties of handsheets with only a slight effect in relation to the sheet density. Improvements in strength properties of handsheets such as z-strength, tensile index, tear index, burst index, Emodulus, strain at break, tensile stiffness, air resistance were observed.

\section{ADDRESSES OF THE AUTHORS: \\ Sinke H. Osong (henshaw.sinke@miun.se), \\ Sven Norgren (sven.norgren@miun.se), \\ Per Engstrand (per.engstrand@miun.se), \\ FSCN, Mid Sweden University, 851 70, Sundsvall. \\ Corresponding author: Sinke H. Osong}

As early as 1983, pulp fibres were treated in a high pressure homogenizer to produce thread-like fibre particles known as microfibrillated cellulose (MFC) or nanocellulose (Turbak et al. 1983; Herrick et al. 1983). In recent years, there has been tremendous work in the research field of nanocellulose (Andresen et al. 2006; Henriksson et al. 2007; Pääkkö et al. 2007; Eichhorn et al. 2010; Spence et al. 2010a; Spence et al. 2010b) but, few scholars have envisaged the use of the low quality fine fractions that is generated in a mechanical pulping process as stock material for the production of nanoligno-cellulose (NLC). The name nano-ligno-cellulose is used in this work and is not the commonly used names such as nanocellulose, microfibrillated cellulose, nanofibrillated cellulose, nanofibres, nanofibrils and microfibrils as reported in Klemm et al. (2011). This is because the "nanofibres" produced in this work contains lignin, and as such the term NLC is preferred in this study. Today, it has been noticed by many that the global consumption of mechanical pulping products most especially newsprints, uncoated and coated papers in the market are in a decline while tissue, containerboards and cartonboards seems to have a fairly good global growth in demand (Johnsson 2013). This adverse situation of newsprints, uncoated and coated papers in the mechanical pulping market could be somewhat alleviated by possibly searching for better products or by improving the material quality of existing products (paper/board qualities). One of the critical properties for paper products such as paper board, tissue and fluff is high bulk (low density) at a desired strength (Höglund, Wilhelmsson 1993). A good historical review of the development of different mechanical pulps is well elucidated in the Bøhmer (1986) article.

When discussing nanocellulose production, it is fairly easy to picture the huge amount of energy consumption (Spence et al. 2011) and the issue of fibre clogging in the mechanical homogenizing/microfluidizing equipment (Ankerfors 2012). It is important that researchers investigate possible good methods in relation to producing nanocellulose in an energy-efficient manner (Pääkkö et al. 2007; Ankerfors 2012). Several pretreatment methods such as TEMPO $(2,2,6$, 6tetramethylpiperidine-1-oxyl radical)-mediated oxidation (Saito et al. 2007), enzymatic process (Henriksson et al. 2007; Pääkkö et al. 2007 ), and carboxymethylation (Wågberg et al. 1987; Wågberg et al. 2008) have been applied with regards to reducing the energy consumption during nanocellulose processing, which is a fundamental aspect for industrial production. Nanocellulose could prove to be interesting for several applications including; pharmaceuticals, medical, coatings, food, paper and paperboard.

Due to the inherent high strength properties of nanocellulose, it is possible to use these as a strength reinforcement agent in the pulp and paper industry. The potential of nanocellulose and nanocomposites in a comprehensive overview is given in the review paper of Eichhorn et al. (2010). For fibre strength enhancement, several schools of thoughts have used refining, beating and/or chemical additives to improve the strength in paper and paperboard applications (Mohlin, Alfredsson 1990; Dasgupta 1994; Saito, Isogai 2005; Duker et al. 2007, Duker, Lindström 2008; Ankerfors et al. 2013). Careful studies of the tensile strength of paper by Page (1969) have revealed that the strength property of paper is dependent on the fibre length, fibre density, fibre strength, the ratio of cross-sectional area to perimeter, fibre-fibre interaction and the relative bonded area. Another way of improving paper strength is by blending pulp fibres with nanocellulose.

There have been several trials involving the use of nanocellulose as a strength additive (Nakagaito, Yano 2005; Ahola et al. 2008, Eriksen et al. 2008; Nakagaito et al. 2009; Taipale et al. 2010; Zimmermann et al. 2010; Sehaqui et al. 2011; Hii et al. 2012; Sehaqui et al. 2013). Eriksen et al. (2008) highlighted that, by blending 4\% of bleached kraft pulp MFC with TMP fibre furnish, this 


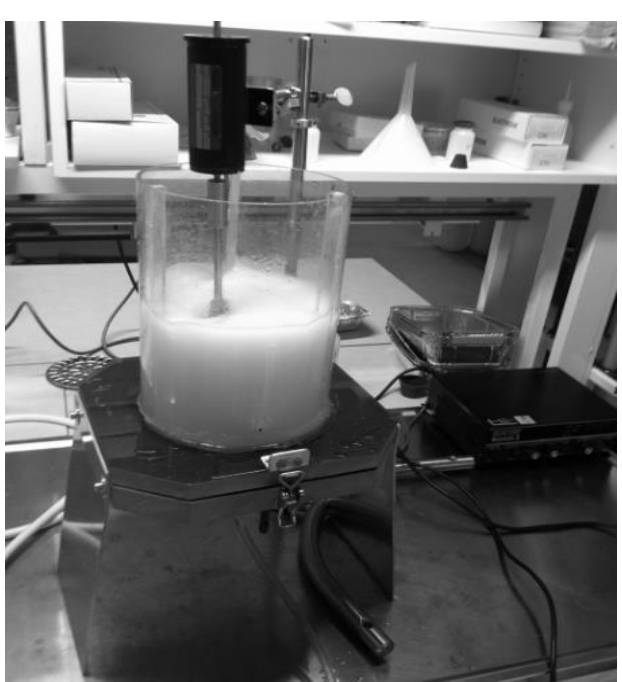

Fig 1a - A specially designed BDDJ

improved the tensile index and air resistance. Taipale et al. (2010) and Hii et al. (2012) blended MFC with pulp suspension and noticed an increase in paper strength and a decrease in pulp dewatering. Spence et al. (2010) have produced TMP-based nanocellulose and have noticed that it was difficult to extract well individualized fibrils from TMP, and, they reported an average fibre diameter within the micron scale. Osong et al. (2013) mentioned that, high temperature homogenisation of up to about $140^{\circ} \mathrm{C}$ could improve the degree of fibrillation by affecting the softening of lignin and, in addition, affecting the swelling behaviour of the fibres.

So far, chemical pulp fibres have been utilized as conventional stock materials for nanocellulose production. The main aim of this work is to use stock materials from mechanical or chemi-thermomechanical pulping process to produce lignin containing nanofibres, which are referred to as nano-ligno-cellulose (NLC) in this study. It should be kept in mind that nano-lignocellulose is not the commonly used name for nanocellulose or microfibrillated cellulose (MFC), but in the study it is used as such. The present study shows the influence on handsheets of chemi-thermomechanical pulp (CTMP) fibres blended with NLC. For comparison reasons, nanocellulose (NC) from bleached kraft pulp (BKP) was produced in a similar approach as NLC. Both the NLC and the NC were blended with their respective pulp fibres and their corresponding handsheets properties were evaluated with respect to sheet density.

\section{Materials and Methods}

\section{Chemi-thermomechanical pulp (CTMP)}

The CTMP sample used in this investigation was obtained from SCA Östrand pulp mill, Sundsvall, Sweden. The wood material used was solely never-dried fresh softwood Norway spruce (Picea abies), with a high Canadian Standard Freeness (CSF) of about $619 \mathrm{ml}$ and an ISO brightness of $76 \%$. The pulp was stored in a refrigerator before use. The CTMP was used both as fibre material in the laboratory handsheets and to produce NLC (nanocellulose produced from CTMP is referred to as NLC in this work).

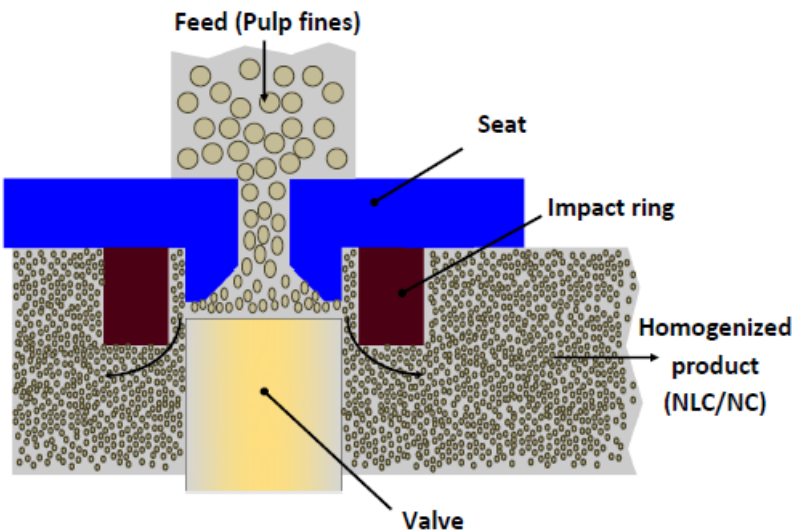

Fig $1 \mathrm{~b}$ - Schematic diagram of a homogenizer

\section{Bleached kraft pulp (BKP)}

The BKP pulp used in this work was collected from SCA Östrand pulp mill, Sundsvall, Sweden. It is of Canadian Standard Freeness (CSF) of about $630 \mathrm{ml}$. $100 \%$ softwood and a mix of Norway spruce (Picea abies) and Scots pine (Pinus sylvestris) at $76 \%$ pine and $24 \%$ spruce, with a mixture of round wood chips $(55 \%)$ and saw mill chips $(45 \%)$ that contained much sapwood. The sapwood is rich in long stiff fibres. The pulp was stored in a refrigerator before use. The BKP was also used both as fibre material in the laboratory handsheets and to make $\mathrm{NC}$ (nanocellulose produced from BKP is referred to NC in this work).

\section{PulpEye® Analyzer}

The fibre quality measurements were done at Dynäs Mondi Mill in Kramfors, Sweden, and the measurement we done manually (offline) using the PulpEye ${ }^{\circledR}$ Online Analyzer (PulpEye AB, 2005, Örnsköldsvik-Sweden). $20 \mathrm{~g}$ dry solid content of pulp was used in all investigations.

\section{Britt Dynamic Drainage Jar (BDDJ) fractionation}

The fine fractions were obtained from the pulp samples (CTMP and BKP) by a fractionation technique. The fractions passing through the 30 mesh screen were considered as "fines" and were used for mechanical treatment in the homogenizer while the retained fractions on the 30 mesh wire were discarded. In this paper, the pulps were fractionated using a specially designed BDDJ (Fig $1 a$ ) at the SCA Research Centre in Sundsvall, Sweden. The cut-off or pore size of the BDDJ 30 mesh screen was approximately $600 \mu \mathrm{m}$. It should be noted that the BDDJ fractionation used in this work was not according to the standard. Further, it is also worth noting that fibre fractionation is not only about the pore size of the wire but, additionally, the quantity of the dry solid content of the pulp and the quantity of water used in the screening process. In this investigation, $30 \mathrm{~g}$ dry solid content pulp was used as well as 8 litres of tap water per fractionation with the 30 mesh screen. The pulp fraction taken for mechanical homogenisation was the P30 (i.e. 
Table 1 - Properties of laboratory sheets and standard methods

\begin{tabular}{|c|c|c|}
\hline $\begin{array}{l}\text { Handsheets } \\
\text { properties }\end{array}$ & Methods & Name of Instruments \\
\hline $\begin{array}{l}\text { Density } \\
\text { (grammage/thickness) } \\
\left(\mathrm{kg} / \mathrm{m}^{3}\right)\end{array}$ & $\begin{array}{l}\text { ISO } 5270 \\
(n=8)\end{array}$ & $\begin{array}{l}\text { Grammage - Mettler } \\
\text { Toledo, Switzerland. } \\
\text { Thickness - L \& W } \\
\text { Sweden }\end{array}$ \\
\hline Tensile index (kNm/kg) & $\begin{array}{l}\text { ISO 1924- } \\
3(n=8)\end{array}$ & $\begin{array}{l}\mathrm{L} \& \mathrm{~W} \text { tensile strength } \\
\text { tester, Sweden }\end{array}$ \\
\hline E-modulus (GN/m²) & $\begin{array}{l}\text { ISO 1924- } \\
3(n=8)\end{array}$ & TH-I L\&W, Sweden \\
\hline $\begin{array}{l}\text { Tensile energy } \\
\text { absorption (TEA) (J/kg) }\end{array}$ & $\begin{array}{l}\text { ISO 1924- } \\
3(n=8)\end{array}$ & TH-I L\&W, Sweden \\
\hline Tear index ( $\left.\mathrm{Nm}^{2} / \mathrm{kg}\right)$ & $\begin{array}{l}\text { ISO } 5270 \\
(n=3)\end{array}$ & $\begin{array}{l}\mathrm{L} \& \mathrm{~W} \text { tearing tester, } \\
\text { Sweden }\end{array}$ \\
\hline $\begin{array}{l}\text { Porosity Bendtsen } \\
\text { (ml/min) }\end{array}$ & $\begin{array}{l}\text { SCAN } \\
\text { P85 }(n=2)\end{array}$ & $\begin{array}{l}\mathrm{L} \& \mathrm{~W} \text { air permeance } \\
\text { tester, Sweden }\end{array}$ \\
\hline Z-strength $\left(\mathrm{kN} / \mathrm{m}^{2}\right)$ & $\begin{array}{l}\text { ISO } \\
15754 \\
(n=5)\end{array}$ & $\begin{array}{l}\text { L \& W ZD tester, } \\
\text { Sweden }\end{array}$ \\
\hline Burst index $(\mathrm{kPam} 2 / \mathrm{g})$ & $\begin{array}{l}\text { ISO } 2758 \\
(n=8)\end{array}$ & $\begin{array}{l}\text { L \& W bursting } \\
\text { strength tester, } \\
\text { Sweden }\end{array}$ \\
\hline
\end{tabular}

$n=$ sample size

Table 2 - Fibre characterisation using PulpEye Analyzer.

\begin{tabular}{llllll}
\hline $\begin{array}{l}\text { Pulp } \\
\text { samples }\end{array}$ & $\begin{array}{l}\text { SR } \\
(\mathbf{m l})\end{array}$ & $\begin{array}{l}\text { Fibre } \\
\text { length } \\
(\mathbf{m m})\end{array}$ & $\begin{array}{l}\text { Fibre } \\
\text { width } \\
(\boldsymbol{\mu m})\end{array}$ & $\begin{array}{l}\text { Curl } \\
(\mathbf{\%})\end{array}$ & $\begin{array}{l}\text { Fines } \\
(\%)\end{array}$ \\
\hline CTMP & 17.4 & 1.74 & 38.1 & 10.9 & 30.7 \\
BKP & 15.5 & 2.09 & 32.2 & 18.6 & 12.9 \\
\hline
\end{tabular}

SR = Schopper-Riegler.

the "fines" fraction that passed through the 30 mesh wire) while the R30 (long and coarse fibres) fraction was discarded. Prior to BDDJ fractionation, pulps were disintegrated at 30,000 revolutions. The diluted suspension was poured onto a BDDJ 30 mesh wire, equipped with an agitator (400-450 rpm) fixed at the centre and the valve opened for the filtrate to be collected (flow rate $=1.41 / \mathrm{min}$ ).

\section{Nano-ligno-cellulose /nanocellulose production}

A GEA Niro Soavi homogenizer (ARIETE, Model: NS2006H, Serial Number: 8755, 2010, Parma-Italy) was used to produce both NLC and NC. The homogenization pressure was set within the 200-300 bars range. The flow rate of the suspension in the homogenizer is $1.4 \mathrm{l} / \mathrm{min}$ with an estimated 18 passes per trial. An average of approximately 5 litres of pulp suspension was used in the majority of the investigations. A comprehensive description of the homogenizer could be read in Osong et al. (2013). 1\% pulp concentration was used during mechanical homogenization. A schematic diagram of a high pressure homogenizer is seen in Fig $1 b$.

\section{Handsheet Properties}

The various laboratory handsheets were made according to the ISO 5269-2 method, using a Rapid-Köthen sheet former from Paper Testing Instruments (PTI), Pettenbach,
Austria. The sheets were dried at $95^{\circ} \mathrm{C}$ with an applied pressure of $96 \mathrm{kPa}$ for $10 \mathrm{~min}$ and paper testing was performed according to the standard testing climate described in ISO $187\left(23^{\circ} \mathrm{C}\right.$ and $50 \%$ relative humidity). The CTMP was hot disintegrated. In this investigation $\mathrm{z}-$ strength, tensile index, tear index, burst index, Emodulus, tensile energy absorption, strain at break, tensile stiffness, sheet density, porosity Bendtsen were used to follow changes in strength properties, according to standard methods presented in Table 1 .

The tensile strength is recognized as the maximum tensile force per unit width a sheet of paper or any test piece can withstand. The idea of this work was to see if handsheets of pulp fibres blended with NLC/NC could improve the paper strength properties. The mean grammage $\left(\mathrm{g} / \mathrm{m}^{2}\right)$ of the handsheets was $65 \mathrm{~g} / \mathrm{m}^{2}$.

\section{Results and Discussion}

Results from the PulpEye® analyzer are given in Table 2. The results show that the BKP had an average fibre length of $2.09 \mathrm{~mm}$ and $12.9 \%$ amount of fines, meanwhile CTMP had an average fibre length of 1.74 $\mathrm{mm}$ and $30.7 \%$ fine content (Table 2).

A good explanation of the mechanical strength potential of different kinds of pulps might be due to their level of treatment in the refiner. Mohlin and Alfredsson (1990) studied fibre strength development using a Beloit-refiner (FEX), an Escher-Wyss and PFI milling and noticed that the PFI-mill gave the highest strength, the FEX the lowest strength level and the Escher-Wyss beaten pulp were between these two.

This work presents results related to paper strength properties based on testing of handsheets of pulp fibres blended with NLC/NC. To the best of our knowledge, there is lack of scientific description of the role of NLC with respect to its contribution to the strength properties of paper. Tensile index, tensile stiffness, tensile energy absorption (TEA) and stretch to break have been widely used for tensile property of a test piece. The tensile strength property of paper is influenced by the fibre strength and bonding strength (Molin 2002). Rundlöf (2002) studied the tensile index of the various kinds of mechanical pulp handsheets in relation to the amount of fines added. He noticed that, addition of 20\% TMP fines to TMP LWC bleached pulp increased the tensile index from 39 to $43 \mathrm{kNm} / \mathrm{kg}$ (10\% improvement). His result is in relative agreement with handsheets of pulp fibres blended with NLC and NC in this work.

The strengthening effect of NLC/NC is somewhat related to the degree of fibrillation of the particles in the homogenizer. In this study, the fibrillation efficiency in chemi-thermomechanical pulp fines was not as good as that of bleached kraft pulp fines. The most reasonable explanation could be that the BKP fines have much higher cellulose content compared to the fines fraction of the hemicellulose and lignin-rich CTMP. During homogenization, it is suspected that the hemicellulose and lignin in the chemi-thermomechanical pulp fines prevent complete individualization of the fine particles into fibrils. 


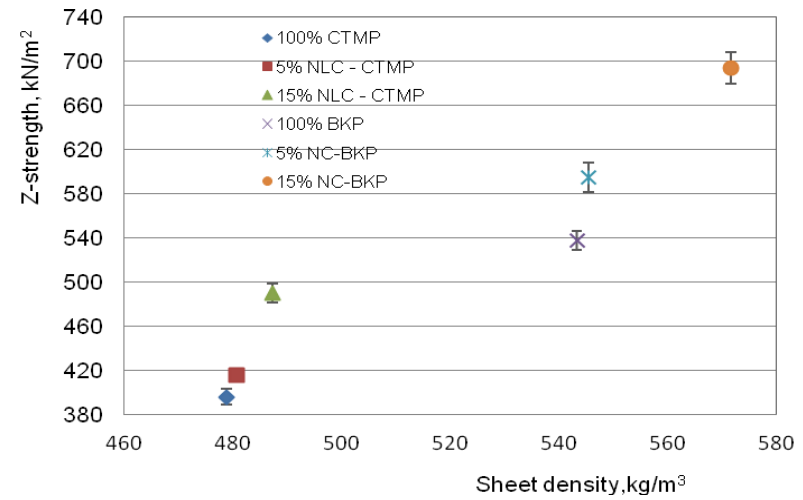

Fig 2 - The z-strength as a function of sheet density for CTMP and BKP

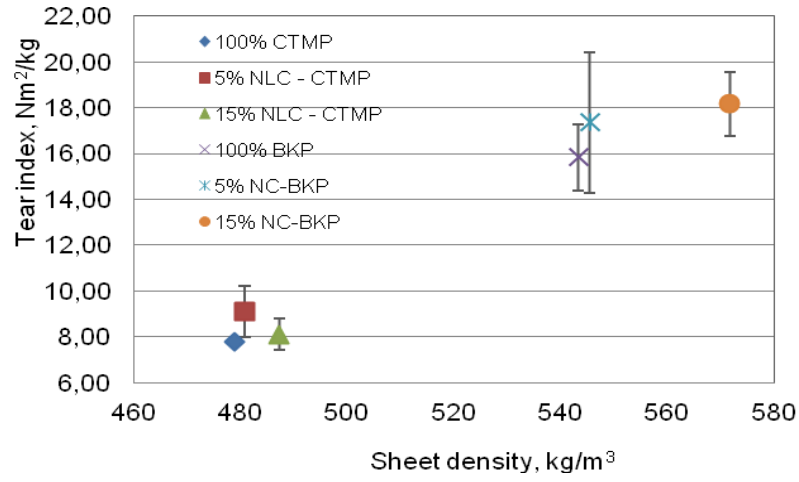

Fig 4 - The tear index versus sheet density for CTMP and BKP

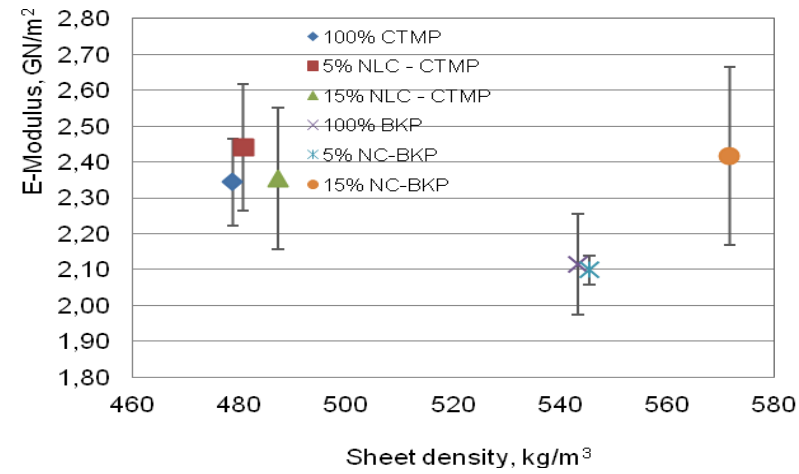

Fig 6 - E-modulus plotted against sheet density for CTMP and BKP

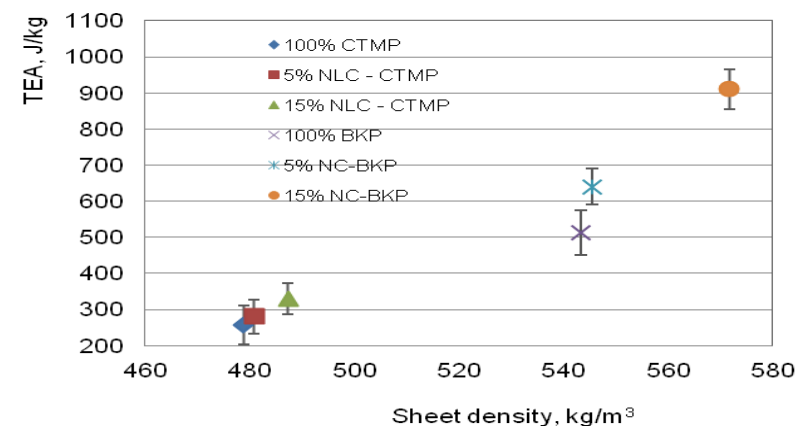

Fig 8 - The TEA as a function of sheet density for CTMP and BKP

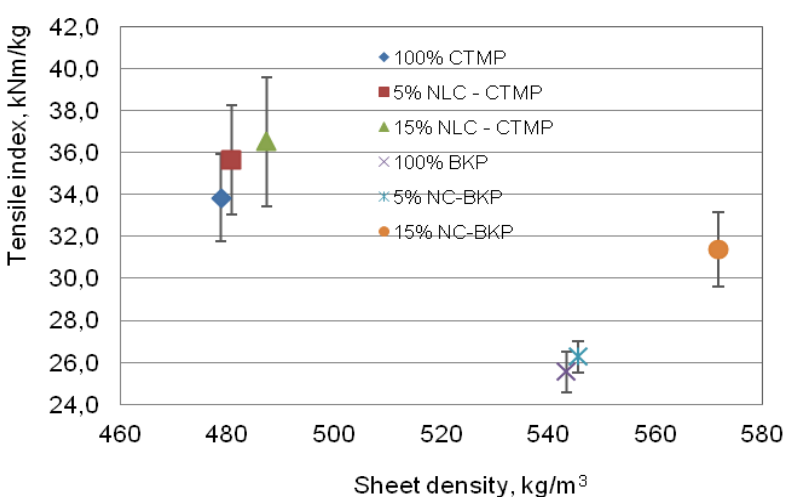

Fig 3 - The tensile index as a function of sheet density for CTMP/BKP

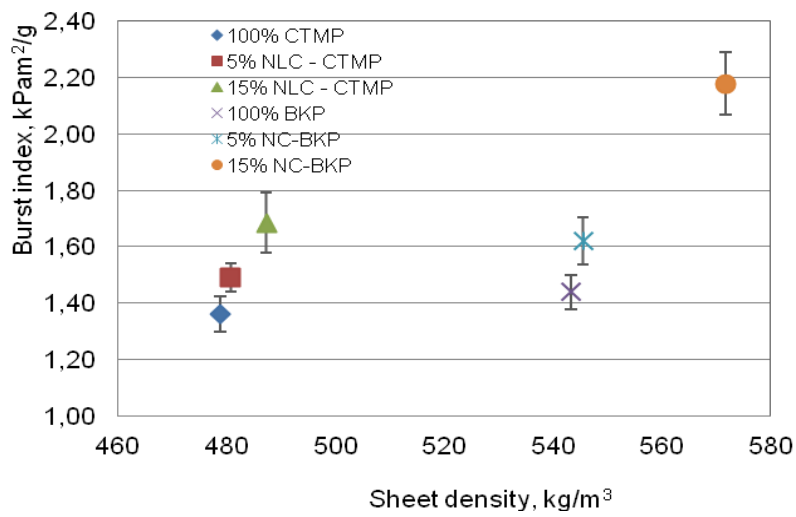

Fig 5 - The burst index versus sheet density for CTMP and BKP

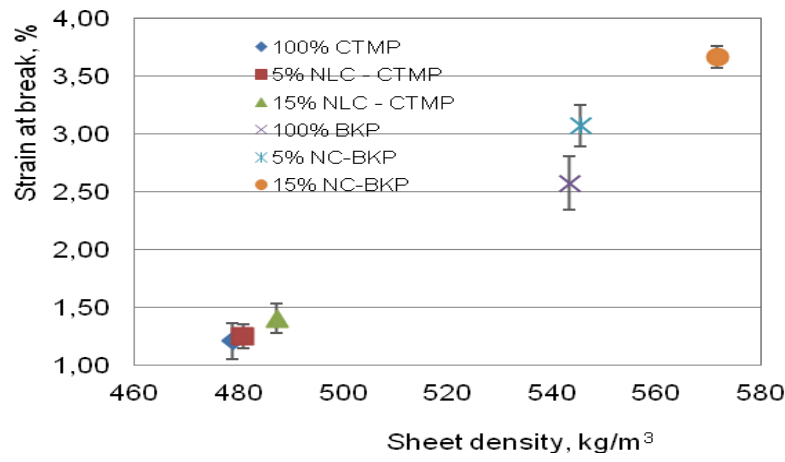

Fig 7 - The influence of NLC/NC addition to CTMP/BKP on Strain at break

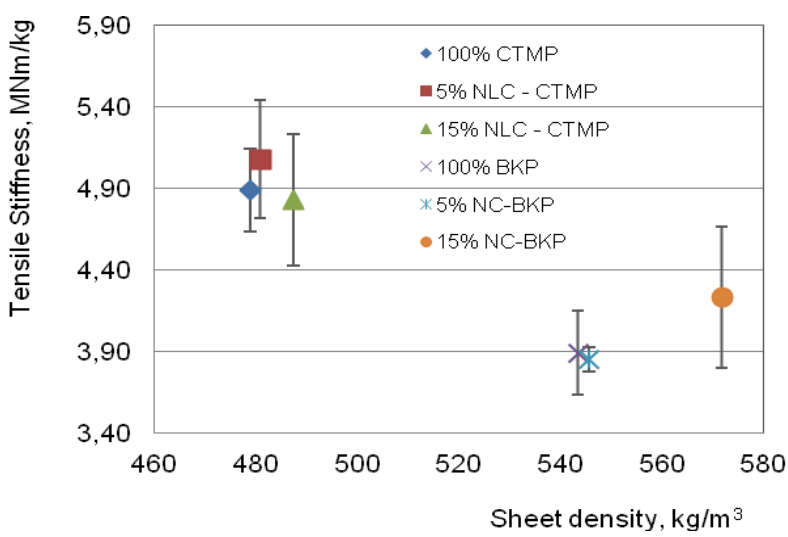

Fig 9 - The tensile Stiffness versus sheet density for CTMP and BKP 


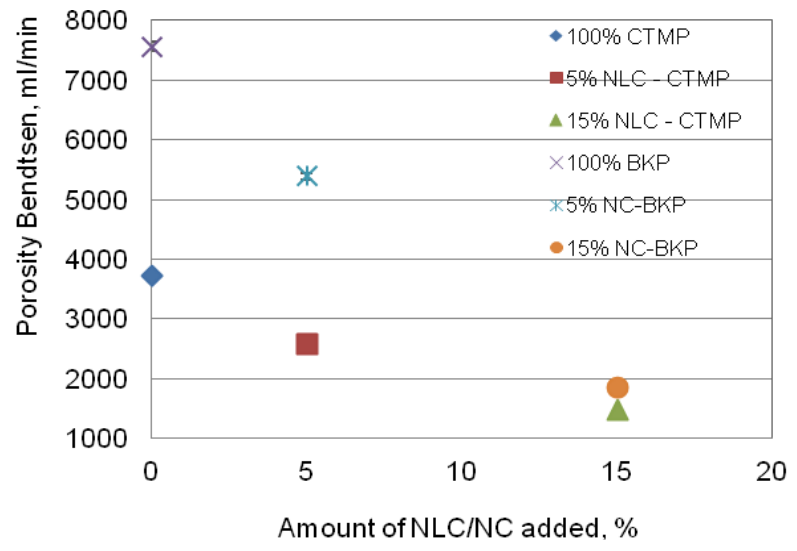

Fig 10 - The influence of NLC/NC addition on CTMP/BKP sheet porosity

Improvements in strength properties of handsheets such as z-strength, tensile index, tear index and burst index, Emodulus, strain at break, tensile stiffness, air resistance were observed (Fig 2-10). Molin (2002) highlighted that the strength properties of handsheets are influenced by additives, formation and flocculation, and also mentioned that tear index investigates the energy used in tearing the paper in the out-of-plane direction. As well described by Page (1969), the tensile strength of paper sheets depend both on the fibre strength and on the bond strength between the individual fibres. Strength property is a function of pulp/fibre type, and other sub-properties that influence paper strength include; fibre flexibility, amount of fines content, degree of fibrillation (both internal and external) and the bondability of the fibre network. The $\mathrm{z}-$ strength is referred to the tensile strength in the $\mathrm{z}$ direction. In previous work by Andersson (1978), he showed that mechanical pulp fibres exhibit superior $\mathrm{z}^{-}$ strength than chemical pulps at a given density in the low-density periphery.

In this present work, it was found that the handsheets of pulp fibres blended with NLC/NC improved the mechanical properties of handsheets with only a slight effect in relation to the sheet density. Fig 2 shows both influence on NC/NLC on both the z-strength and the sheet density. It is clearly seen in that BKP mixed with $\mathrm{NC}$ exhibits superior z-strength property and as well have higher fibre sheet densities than CTMP mixed with NLC.

The results for $\mathrm{z}$-strength, tensile index, tear index, burst index, E-modulus, strain at break, tensile energy absorption (TEA), and tensile stiffness all plotted against sheet density are presented in Fig 2-9. The data for zstrength and tensile index as functions of sheet density are plotted in Fig 2 and 3 respectively where the anticipated trends are evident. At a given sheet density, both the CTMP and the BKP blended with NLC and NC respectively exhibit significantly improved $\mathrm{z}$-strength and tensile index in comparison to the non-mixed samples (100\% CTMP and 100\% BKP). The relationship for the tear index and burst index as functions of sheet density are shown in Fig 4 and 5 respectively. It is well known that the tear strength is primarily a function fibre length, the bonding potential of the pulp fibres having just a secondary effect. The data presented in Fig 4 somewhat does not show a clear trend for CTMP blended samples, but however indicates higher tear index for BKP blended samples. There is also a significant improvement in burst index for both CTMP and BKP blended with their respective NLC and NC. Results for air resistance (porosity Bendtsen) versus amount of NLC/NC added are presented in Fig 10. It was noticed that the more NLC/NC is added onto the pulp fibres, their corresponding sheet porosity reduces. It is clearly seen in Fig 2-9 that the mechanical strength properties for both pulps, i.e. CTMP and BKP were affected by mixing with NLC and NC respectively.

By comparing the z-strength property of NLC-CTMP with that of NC-BKP, NC-BKP showed a better strengthening effect than NLC-CTMP, but NLC-CTMP has a considerably lower sheet density as opposed to BKP. The same goes for the rest of the mechanical properties. Since high bulk at a given strength is of utmost importance in packaging application. It is important to development a high z-strength at a relative low sheet density.

Tensile strength is recognized in terms of relative bonded area in the fibre network (Page 1969). One of the drawbacks of using beating/refining to improve paper strength property is that it leads to paper densification (Sehaqui et al. 2013), which is not good for packaging applications. Sehaqui et al. (2013) noticed that addition of nanofibrillated cellulose (NFC) to pulp fibres had similar effect as pulp beating. They also showed that $10 \%$ NFC reinforced pulp fibre handsheet had a tensile index of 69 $\mathrm{Nm} / \mathrm{g}$ and TEA of $67 \mathrm{~J} / \mathrm{m}^{2}$. The tensile index reported in this work was $36 \mathrm{kNm} / \mathrm{kg}$ for $15 \%$ NLC-CTMP and 31 $\mathrm{kNm} / \mathrm{kg}$ for $15 \%$ NC-BKP. And the TEA was $330 \mathrm{~J} / \mathrm{kg}$ for $15 \%$ NLC-CTMP and $910 \mathrm{~J} / \mathrm{kg}$ for $15 \%$ NC-BKP. The drawback of Sehaqui et al. (2013) work is that they used paper sheets with higher densities than usual paper product, which of course is not suitable for packaging application.

Taipale et al. (2010) commented that the fibre network strength could be increased by increasing the number of bonds. Strength development by the addition of NLC or $\mathrm{NC}$ is closely associated with fibre beating (Mohlin, Alfredsson 1990). It could be possible to attribute the improvement in paper strength properties to an improved fibre network consolidation between the thread-like particles of NLC/NC and the pulp fibre surfaces. Previous studies of tensile strength development using refining (Lumiainen 1998), it can be seen that refining/beating improves the tensile strength of paper in a similar manner to that for the addition of NLC or NC content to fibres.

From the figures presented (Fig 2-9), it is clearly seen that NC provide a better strengthening effect than NLC. The reason might be because of their different bonding abilities. NC fibril is composed mainly of cellulose, hence providing a good bonding potential whereas, the NLC consists of three substances: cellulose, hemicellulose and lignin and thus having a poor bonding tendency due to the presence of lignin. Another possible explanation could be due to fibrillation efficiency; the 
presence of lignin in the NLC somewhat hinders a proper individualization of the fibrils due to the gluing nature oflignin onto cellulose. It has been shown that chemical pulp based nanocellulose acts as strength enhancer in the handsheets (Eriksen et al. 2008) but our main concern was to investigate whether NLC could behave in a similar manner. The results from Fig 2-9 indicate that the addition of NLC/NC to pulp fibres handsheets improved the mechanical properties, causing only a slight effect in the sheet density. With regards to the z-strength of CTMP handsheet, an increase of up to $23 \%$ was noticed using $15 \%$ NLC and $85 \%$ CTMP, see Table 3, which is a good indication for reinforcement in packaging applications.

One question is whether all the NLC or NC used during laboratory sheet making process was retained. In this investigation, it should be noted that some amount of NLC/NC fractions were loss during the sheet forming process in the Rapid-Köthen equipment. But since all the trials were carried out at the same conditions, it is reasonable to compare the results obtained in this work. Although the judgment of the results obtained would not exactly reflect a $5 \%$ or $15 \%$ blend of NLC/NC but it will definitely give an indication if higher or lower amounts of
NLC/NC can significantly improved paper strength properties. It is also important to note that there were no significant differences in terms of the retention time in relationship between the various pulp fibres (CTMP and BKP) blended with nano-ligno-cellulose or nanocellulose during laboratory sheet formation using the RapidKöthen equipment. For the NLC/NC obtained in this work was not in a gel form but rather like a suspension.

\section{Conclusions}

The strength properties of pulp fibres handsheets were increased using by NLC and NC and, this caused only a slight effect in relation to the sheet density. In general, the strength properties of pulp fibres handsheets blended with NC/NLC showed better strength than those that were not mixed NLC/NC. For comparison between NC and NLC in term of strengthening effect; it was seen that the NC showed somewhat better strength properties than NLC. It is however important to bear in mind that there is still need for improvement in terms of the pulp fibre degree of fibrillation after homogenization.

Table 3 - Summary of mechanical properties of handsheets made from Rapid Köthen Machine using CTMP and BKP

\begin{tabular}{|c|c|c|c|c|c|c|c|}
\hline \multicolumn{2}{|c|}{ Properties } & \multicolumn{3}{|c|}{ \%NLC-CTMP } & \multicolumn{3}{|c|}{$\%$ NC-BKP } \\
\hline & & $0 \%$ (ref.) & $5 \%$ & $15 \%$ & $0 \%$ (ref.) & $5 \%$ & $15 \%$ \\
\hline Z-strength & Value & $396 \pm 1.8$ & $416 \pm 0.92$ & $490 \pm 1.7$ & $538 \pm 1.6$ & $595 \pm 2.3$ & $694 \pm 2.1$ \\
\hline$\left(\mathrm{kN} / \mathrm{m}^{2}\right)$ & Change from ref. & 0 & $+5 \%$ & $+24 \%$ & 0 & $+11 \%$ & $+29 \%$ \\
\hline Tensile index & Value & 33.8 & 35.6 & 36.5 & 25.5 & 26.3 & 31.4 \\
\hline$(\mathrm{kNm} / \mathrm{kg})$ & Change from ref. & 0 & $+5 \%$ & $+8 \%$ & 0 & $+3 \%$ & $+23 \%$ \\
\hline Tear index & Value & 7.77 & 9.13 & 8.12 & 15.83 & 17.36 & 18.16 \\
\hline$\left(\mathrm{Nm}^{2} / \mathrm{kg}\right)$ & Change from ref. & 0 & $+17 \%$ & $+4.5 \%$ & 0 & $+10 \%$ & $+15 \%$ \\
\hline Burst index & Value & 1.36 & 1.49 & 1.69 & 1.44 & 1.62 & 2.18 \\
\hline$\left(\mathrm{kPam}^{2} / \mathrm{g}\right)$ & Change from ref. & 0 & $+9 \%$ & $+24 \%$ & 0 & $+12 \%$ & $+51 \%$ \\
\hline E-modulus & Value & 2.34 & 2.44 & 2.35 & 2.11 & 2.10 & 2.42 \\
\hline$\left(\mathrm{GN} / \mathrm{m}^{2}\right)$ & Change from ref. & 0 & $+4 \%$ & $+0.4 \%$ & 0 & $-0.5 \%$ & $+14 \%$ \\
\hline Strain at break & Value & 1.21 & 1.25 & 1.41 & 2.58 & 3.07 & 3.67 \\
\hline$(\%)$ & Change from ref. & 0 & $+3 \%$ & $+16 \%$ & 0 & $+19 \%$ & $+42 \%$ \\
\hline Tensile energy & Value & 257 & 280 & 330 & 512 & 640 & 910 \\
\hline Absorption (J/kg) & Change from ref. & 0 & $+9 \%$ & $+28 \%$ & 0 & $25 \%$ & $+78 \%$ \\
\hline Porosity Bendtsen & Value & $3735 \pm 0.2$ & $2585 \pm 0.3$ & $1480 \pm 0.0$ & $7565 \pm 1.0$ & $5390 \pm 1.0$ & $1865 \pm 0.4$ \\
\hline (ml/min) & Change from ref. & 0 & $-31 \%$ & $-60 \%$ & 0 & $-29 \%$ & $-75 \%$ \\
\hline Tensile stiffness- $x$ & Value & 4.89 & 5.08 & 4.83 & 3.89 & 3.85 & 4.23 \\
\hline$(\mathrm{MNm} / \mathrm{kg})$ & Change from ref. & 0 & $+4 \%$ & $-1 \%$ & 0 & $-1 \%$ & $+9 \%$ \\
\hline Sheet density & Value & 479 & 481 & 487 & 543 & 546 & 572 \\
\hline$\left(\mathrm{kg} / \mathrm{m}^{3}\right)$ & Change from ref. & 0 & $+0.4 \%$ & $+2 \%$ & 0 & $+0.5 \%$ & $+5 . \%$ \\
\hline
\end{tabular}




\section{Acknowledgements}

This study is a part of the Mid Sweden University "FORE" programme. The authors would like to thank European Union and Länsstyrelsen i Västernorrland for their financial support. Special thanks to Majid Alimadadi who kindly did the schematic diagram of the homogenizer.

\section{Literature}

Ahola, S., Österberg, M., Laine, J. (2008): Cellulose nanofibrils-adsorption with poly (amideamine) epichlorohydrin studied by QCM-D and application as a paper strength additive, Cellulose, vol. 15, no. 2, pp. 303-314.

Andersson, M. (1978): Aspects of the Z-strength in pulp characterisation. Doctoral Thesis, Royal Institute of Technology, Stockholm, Sweden

Andresen, M., Johansson L.S., Tanem, B.S., Stenius, P. (2006): Properties and characterization of hydrophobized microfibrillated cellulose. Cellulose, 13(6), 665-677.

Ankerfors, M. (2012): Microfibrillated cellulose: Energy-efficient preparation techniques and key properties. Licentiate Thesis, Department of Fibre and Polymer Technology, Royal Institute of Technology, Stockholm, Sweden.

Ankerfors, M., Duker, E., Lindström, T. (2013): Topochemical modification of fibres by grafting of carboxymethyl cellulose in pilot scale, Nord. Pulp Paper Res. J., Vol 28, no.1, pp. 6-14.

Bøhmer, E. (1986): The production and use of mechanical and chemi-mechanical pulps, Nord. Pulp Paper Res. J., no.4, pp. 4 12.

Dasgupta, S. (1994): Mechanism of Paper Tensile-Strength Development Due to Pulp Beating, Tappi Journal, 77(6), 158166.

Duker, E. and Lindström, T. (2008): On the mechanisms behind the ability of CMC to enhance paper strength, Nord Pulp Paper Res. J., Vol 23, no.1, pp 57-64.

Duker, E., Brännvall, E., Lindström, T. (2007): The effects of CMC attachment onto industrial and laboratory-cooked pulps, Nord. Pulp Paper Res. J., Vol.22 no.3, pp 356-363.

Eichhorn, S. J., Dufresne, A., Aranguren, M., Marcovich, N. E., Capadona, J. R., Rowan, S. J., Weder, C., Thielemans, W., Roman, M., Renneckar, S., Gindl, W., Veigel, S., Keckes, J., Yano, H., Abe, K., Nogi, M., Nakagaito, A. N., Mangalam, A., Simonsen, J., Benight, A. S., Bismarck, A., Berglund, L. A., Peijs, T. (2010): Review: current international research into cellulose nanofibres and nanocomposites. J. of Materials Science, 45(1), 1-33.

Eriksen, Ø., Syverud, K., Gregersen, Ø. (2008): The use of microfibrillated cellulose produced from kraft pulp as strength enhancer in TMP paper, Nord. Pulp Paper Res. J., Vol 23, no.3, pp. 299-304

Henriksson, M., Henriksson, G., Berglund, L., Lindström, T. (2007): An environmentally friendly method for enzyme-assisted preparation of microfibrillated cellulose (MFC) nanofibers. European Polym. J., 43(8), 3434-3441.

Herrick, F., Casebier, R., Sandberg, K. (1983): Microfibrillated cellulose: morphology and accessibility. J. Appl. Polym. Sci.: Appl. Polym. Symp 37:797-813 (United States) ITT Rayonier Inc., Shelton, WA.
Hii, C., Øyvind W. Gregersen, Gary Chinga-Carrasco, Øyvind Eriksen (2012): The effect of MFC on the pressability and paper properties of TMP and GCC based sheets, Nord. Pulp Paper Res. J., Vol.27 no.2, pp388-396.

Höglund, H. and Wilhelmsson, K. (1993): The product must determine the choice of wood type in mechanical pulping, International Mechanical Pulping Conference, Oslo, Norway, pp1-22.

Johnsson, M. (2013) : Mechanical pulping market challenges, $8^{\text {th }}$ International Fundamental Mechanical Pulp Research Seminar, 29-31 Jan 2013, Åre, Sweden, pp128-137.

Klemm, D., Kramer, F., Moritz, S., Lindström, T., Ankerfors, M., Gray, D., Dorris, A. (2011): Nanocelluloses: A New Family of Nature-Based Materials. Angewandte Chemie Int. Edition, 50(24), 5438-5466.

Lumiainen J. (1998): Refining of chemical pulp. In: Paulapuro $\mathrm{H}$. (ed) Papermaking science and technology, book 8 papermaking part 1, stock preparation and wet end. Fapet Oy, Helsinki.

Mohlin, U-B and Alfredsson, C. (1990): Fibre deformation and its implications in pulp characterization, Nord. Pulp Paper Res. J., no.4, pp 172-179.

Molin, U. (2002): Pulp strength properties - Influence of carbohydrate composition, molar mass and crystalline structure, Doctoral Thesis, Department of Pulp and Paper Chemistry and Technology, Royal Institute of Technology, Stockholm, Sweden.

Nakagaito, A.N., Fujimura, A., Sakai, T., Hama, Y., Yano, H. (2009): Production of microfibrillated cellulose (MFC)-reinforced polylactic acid (PLA) nanocomposites from sheets obtained by a papermaking-like process, Composite Science and Technology 69, pp1293-1297.

Nakagaito, A.N and Yano, H. (2005): Novel high-strength biocomposites based on microfibrillated cellulose having nanoorder-unit web-like network structure, Appl. Phys. A 80, pp155159 (2005).

Osong, S.H., Norgren, S., Engstrand, P. (2013): An approach to produce nano-ligno-cellulose from mechanical pulp fine materials, Nord. Pulp Paper Res. J., accepted for Publication, Vol 28, no.4

Pääkkö, M., Ankerfors, M., Kosonen, H., Nykänen, A., Ahola, S., Österberg, M., Ruokolainen, J., Laine, J., Larsson, P.T., Ikkala, O. and Lindström, T. (2007): Enzymatic hydrolysis combined with mechanical shearing and highpressure homogenization for nanoscale cellulose fibrils and strong gels. Biomacromolecules, 8(6), 1934-1941.

Page, D.H. (1969): A theory for the tensile strength of paper, TAPPI, Vol. 52, No. 4, pp674-681.

Rundlöf, M. (2002): Interaction of dissolved and colloidal substances with fines of mechanical pulp-Influence on sheet properties and basic aspects of adhesion, Doctoral Thesis, Department of Wood Chemistry, Royal Institute of Technology, Stockholm, Sweden.

Saito, T., Isogai, A. (2005): A novel method to improve wet strength of paper, TAPPI JOURNAL, Vol. 4: No.3.

Saito, T., Kimura, S., Nishiyama, Y., Isogai, A. (2007): Cellulose nanofibers prepared by TEMPO-mediated oxidation of native cellulose. Biomacromolecules, 8(8), 2485-2491. 
Sehaqui, H., Zhou, Q., and Berglund, L. A. (2013): Nanofibrillated cellulose for enhancement of strength in highdensity paper structures, Nord. Pulp Paper Res. J., Vol 28, no.2, pp 182-189.

Sehaqui, H., Allais, M., Zhou, Q., Berglund, L. A. (2011) Wood cellulose biocomposites with fibrous structures at microand nanoscale, Composites Science and Technology 71, 382387.

Spence, K. L., Venditti R. A., Rojas, O.J., Habibi, Y., Pawlak, J.J. (2011): A comparative study of energy consumption and physical properties of microfibrillated cellulose produced by different processing methods. Cellulose, 18(4), 1097-1111.

Spence, K. L., Venditti., R. A., Habibi, Y., Rojas., O. J., Pawlak., J. J. (2010a): The effect of chemical composition on microfibrillar cellulose films from wood pulp: Mechanical processing and physical properties. Bioresource Technology 101, 5961-5968

Spence, K. L., Venditti., R. A., Rojas., O.J., Habibi, Y., Pawlak., J. J. (2010b): The effect of chemical composition on microfibrillar cellulose films from wood pulps: water interactions and physical properties for packaging applications. Cellulose 17: 835-848
Taipale, T., Österberg, M., Nykänen, A., Ruokolainen, J., Laine, J. (2010): Effect of microfibrillated cellulose and fines on the drainage of kraft pulp suspension and paper strength, Cellulose 17: pp1005-1020.

Turbak, A., Snyder, F., Sandberg, K. (1983): Microfibrillated cellulose, a new cellulose product: properties, uses, and commercial potential. J. Appl. Polym. Sci.: Appl. Polym. Symp. 37: 815-827.

Wågberg, L., Decher, G., Norgren, M., Lindström, T., Ankerfors, M., Axnäs, K. (2008): The Build-Up of Polyelectrolyte Multilayers of Microfibrillated Cellulose and Cationic Polyelectrolytes, Langmuir 2008, 24, pp784-795.

Wågberg, L., Winter, L., Ödberg, L., Lindström, T. (1987): On the charge stoichiometry upon adsorption of a cationic polyelectrolyte on cellulosic material, Colloids and Surfaces, 27, pp163-173.

Zimmermann, T., Bordeanu, N., Strub, E. (2010): Properties of nanofibrillated cellulose from different raw materials and its reinforcement potential, Carbohydrate Polymers 79, pp10861093.

Manuscript received September 17, 2013 Accepted November 21, 2013 